\title{
ORIENTAÇÃO VOCACIONAL EM UMA UNIVERSIDADE PÚBLICA DO ESTADO DE MINAS GERAIS: UM OLHAR PARA O FUTURO
}

\author{
VOCATIONAL ORIENTATION IN A PUBLIC UNIVERSITY OF THE STATE OF MINAS \\ GERAIS: A LOOK AT THE FUTURE
}

Izabel Cristina Taceli ${ }^{1}$

Geisiane Rodrigues dos Santos ${ }^{2}$

\section{RESUMO}

Este artigo tem por objetivo central descrever as ações de extensão para orientação vocacional de alunos que estão finalizando o Ensino Médio de Escolas Públicas na cidade de Frutal - MG. E que tem a finalidade de promover a integração com a UEMG - Universidade do Estado de Minas Gerais - MG” e prepará-los para os exames vestibulares, mas necessariamente possibilitar a escolha profissional em um cenário de constantes mudanças devido o surgimento de novas profissões. Os objetivos específicos deste projeto de extensão são de promover a integração de alunos do ensino médio com a universidade, despertando o potencial voltado para as profissões, valorizando-as, ao mesmo tempo em que também reconhece suas limitações, identificar possibilidades de atuação no mercado de trabalho, entrevistar diferentes profissionais, propiciar a partir das dificuldades relacionadas à escolha de cada um e auxilia-los na vida social e a se prepararem para enfrentar uma ocupação. Este artigo pautado na metodologia qualitativa para discutir as questões apresentadas pelos participantes, empregando a abordagem psicanalítica, por se tratar de uma associação com as aptidões e desejos do sujeito. Assim, o desenvolvimento proposto baseou-se no intuito de obter maior reflexão e conhecimento vivencial dos jovens a respeito de conceitos apropriados a temática como a diversidade de profissões, como fazer a escolha profissional, estarem atentos ao mercado de trabalho e adquirir um desejável autoconhecimento e, fortalecendo as relações saudáveis, no âmbito profissional e pessoal e, consequentemente apresentar habilidades importantes para um bom profissional.

Palavras-chave: Educação e Ensino Superior. Orientação vocacional e profissional. Aptidão. Integração.

\section{ABSTRACT}

This article aims to describe the extension actions for vocational guidance of students who are finishing the High School of Public Schools in the city of Frutal - MG. And that has the purpose of promoting the integration with UEMG - University of the State of Minas Gerais - MG "and prepare them for the vestibular exams, but necessarily make possible the professional choice in a scenario of constant changes due to the emergence of new professions. The specific objectives of this extension project are to promote the integration of high school students with the university, awakening the potential for the professions, valuing them, while recognizing their limitations, identifying possibilities of action in the market of work, interview different professionals, propitiate from the difficulties related to the choice of each one and helps them in the social life and to prepare themselves to face an occupation. This article is based on the qualitative methodology to discuss the questions presented by the participants, using the psychoanalytic approach, because it is an association with the subject's aptitudes and desires. Thus, the proposed development was based on the aim of obtaining greater reflection and experiential knowledge of young people regarding concepts appropriate to the theme such as the diversity of professions, how to make a professional choice, be attentive to the labor market and acquire a desirable self-knowledge and, strengthening the healthy relationships in the professional and personal scope and, consequently, presenting important skills for a good professional.

Keywords: Education and College education. Vocational and professional orientation. Aptitude. Integration.

\footnotetext{
${ }^{1}$ Universidade do Estado de Minas Gerais/UEMG - Minas Gerais/Brasil. E-mail: itaceli@ hotmail.com

${ }^{2}$ Universidade do Estado de Minas Gerais/UEMG - Minas Gerais/Brasil. E-mail: geisiane.santos@uemg.br
} 


\section{INTRODUÇÃO}

É fundamental enquanto Universidade ter como foco uma proposta que fortaleça a autoestima, os valores e a responsabilidade social em sua atuação, priorizando os discentes, como o seu principal patrimônio, e, por conseguinte criando reais condições que incentivem a participação da comunidade em geral, em especial alunos com trajetória em escolas públicas. Como versa alguns estudiosos:

Geralmente, até o término do ensino médio, uma significativa parcela da vida dos adolescentes gira em torno da escola: é na escola que passam a maior parte do tempo; é lá que costumam ter a maioria dos amigos; é também, principalmente, a escola que lhes cobra desempenho e responsabilidade, sob pena de sanções diversas. O mundo universitário, por outro lado, é bem menos estruturado que o mundo escolar. Os colegas não são mais os mesmos, havendo a necessidade de estabelecer novos vínculos de amizade. Enquanto tais vínculos não se estabelecem, o jovem conta apenas com seus próprios recursos psicológicos e o apoio das redes formadas anteriormente ao ingresso na universidade (outros amigos e família) para enfrentar eventuais dificuldades que possam surgir pela frente (TEIXEIRA et al. 2008, p.186).

Nota-se que muitos destes alunos chegam até o vestibular idealizando profissões ou cursos, em determinadas ocasiões contam com o apoio da família, amigos, outras precisam aprender a decidirem sozinhos. Nesse contexto se distanciam das próprias aptidões do que propriamente por opções pautadas em análises criteriosas, que necessitem maior assertividade quanto à escolha profissional e acadêmica. Vislumbrar a universidade por meio de um processo de escolha profissional eficaz é fundamental para se estruturar enquanto profissional.

É inquietante a constatação de que um número considerável de recém-graduandos desista da vaga conquistada por se decepcionarem com o curso escolhido. Em visitas realizadas com futuros calouros à universidade, é possível minimizar este quadro preocupante de desistentes e potencializar uma maior interação futura.

Portanto, a ideia de investigar os jovens, bem como suas experiências quanto ao ingresso à universidade, parte inclusive das mudanças por ele enfrentadas e a adaptação à vida universitária no primeiro ano, ouvindo relatos retrospectivos dessa experiência, desde o ingresso no contexto universitário, que por sua vez, tem um papel importante a desempenhar no processo de adaptação à universidade e a superação das dificuldades nesse processo adaptativo.

A vida acadêmica então traz muitas mudanças e, dentre elas exigem um esforço de adaptação do estudante, seja no sentido de corresponder às exigências de desempenho, que lhe é esperado, como notas mais altas, do que no ensino médio, também no sentido de internalizar as diferentes regras frente à instituição, como em especial as novas pessoas, como colegas, professores ou funcionários.

Desta feita, se o aluno inicia bem sua vida acadêmica, fazendo uma boa escolha, a adaptação no mundo universitário, sem dúvida no dia a dia do aluno se torna mais flexível e proveitosa. Assim parafraseada pelos autores: 
O Processo de autoconhecimento é fundamental para a realização uma escolha contextualizada aos desejos individuais (Soares, 2002). Sem reflexão sobre características, gostos, interesses valores, habilidades e metas pessoais, aumenta-se o risco de se realizar uma escolha profissional sem satisfação e alcance dos objetivos (LASSANCE; LEVENFUS; SILVA, 2015, p. 52).

Percebem-se que muitos fatores remetem a uma boa escolha profissional, pois ela reflete nas características intrínsecas do sujeito, assim quanto maior o amadurecimento e autoconhecimento, melhores são as chances de incidir no sucesso da carreira. Cajaíba (2003) aponta igualmente para a questão do autoconhecimento:

Ao que consta ainda há uma difícil tarefa para os jovens nessa etapa da vida: fazer escolhas e projetos para a vida profissional. A dificuldade está na falta do autoconhecimento, apesar de terem acesso à informação através da globalização. A construção do futuro é quando se entende que a autonomia só é permitida aos sujeitos com uma conquista, e que exige paciência para saber esperar, que no caso é um pouco complicado para essa geração que tem prazeres imediatos e sucesso (CAJAÍBA, 2003 apud LASSANCE; LEVENFUS; SILVA, 2015).

$\mathrm{Na}$ orientação do processo da escolha vocacional/profissional pode-se realizar diversos procedimentos e utilizar várias técnicas. Havendo diferentes recursos e estratégias para realização da orientação vocacional, como apontados por alguns autores:

Técnicas de entrevistas, técnicas psicodramáticas, de grupo operativo, entre outras técnicas grupais, podem ser utilizadas de acordo com o referencial teórico e prático que fundamenta a intervenção. Instrumentos de avaliação, tais como inventários de interesse, baterias de aptidões, testes de inteligência e de personalidade, técnicas gráficas, projetivas e expressivas também podem ser utilizados como recursos complementares tendo em vista a facilitação da escolha e desde que os profissionais conheçam os construtos teóricos e as normas para aplicação e interpretação dos resultados obtidos por meio dos instrumentos. Mas, principalmente, que tenham a clareza do porquê, com quem e em que momento inserir alguma técnica, teste ou escala. Os benefícios para o cliente estão acima do interesse do orientador profissional em utilizar certos recursos. O uso de testes, escalas e outros instrumentos de avaliação é recomendado apenas em processos dinâmicos de Orientação Profissional, que abordam questões como: (1) "escolha" da carreira; (2) influências sociais, educacionais, familiares, econômicas e políticas na tomada de decisão; (3) informações sobre as carreiras; (4) significado do trabalho e do mercado de trabalho, entre outros temas emergentes (SILVA; NOCE; ANDRADE, 2003, p.01).

Desta forma, pode optar por diversas técnicas, observando as características e perfis dos alunos analisados e orientando-o para que este possa se adaptar ao contexto da universidade. Projetando-o como futuro aluno, enriquecendo as experiências durante $o$ primeiro ano na universidade, aspectos necessários para resultados futuros, mas primordiais para a permanência no ensino superior, integração e o sucesso acadêmico.

$\mathrm{Na}$ verdade, essa integração pode fazer com que os alunos possam aproveitar melhor as oportunidades oferecidas pela universidade, no sentido da formação profissional ou mesmo para o seu desenvolvimento psicossocial. Observa-se que os estudantes que se interagem academicamente $\mathrm{e}$ socialmente desde o início de seus cursos têm possivelmente mais chances de crescerem intelectualmente e pessoalmente do que aqueles que enfrentam mais dificuldades na transição à universidade, favorecendo um melhor desempenho e aprendizagem. Nesta conexão 
metodológica a fundamentação teórica utilizouse:

A base teórica utilizada é a teoria psicanalítica. O psicólogo que atua no campo da Orientação Vocacional tem uma oportunidade ímpar para adotar medidas psicoprofiláticas. Especialmente, se entendermos a psicoprofilaxia "como toda atividade que, a partir de um plano de análise psicológico e mediante o emprego de recursos e técnicas psicológicas, procure promover o desenvolvimento das potencialidades do ser humano, seu amadurecimento como indivíduo $\mathrm{e}$, finalmente, sua felicidade (ALMEIDA 2014, apud BOHOSLAVSKY, 2007).

A felicidade muitas vezes implica na forma dos alunos melhor ajustar-se à vida na universidade, concomitantemente, integrar-se socialmente com as pessoas neste novo contexto, ao mesmo tempo, o jovem participa de inúmeras atividades sociais e passam a desenvolver relações interpessoais satisfatórias, que se traduzem em novas escolhas no âmbito profissional.

Nesta linha metodológica de pensamento a Psicanálise é analisada:

Em 1950, foram publicadas Teorias Psicodinâmicas da escolha profissional, que tinha como base a Teoria Psicanalítica, a Teoria de Satisfação das Necessidades, e Teorias de Tomada de Decisão que atentava mais com o momento da escolha do que com o processo em si. Em 1951 foi publicado um livro, Occupational Choice, por Ginzberg, Ginsburg, Axelrad e Herma, que trouxe a primeira teoria do Desenvolvimento Vocacional, onde tinha como ideia que a escolha profissional era um processo evolutivo que acontece da infância até o início da vida adulta. No ano de 1970, Ginzberg fez uns ajustes na sua teoria e estabeleceu que a escolha profissional é um processo que acontece durante toda a vida do indivíduo. $\mathrm{O}$ paradigma desenvolvimentista foi bem representado por Donald Super, que publicou a teoria do Desenvolvimento Vocacional, onde defendia a escolha profissional como um processo que acontece ao longo da vida do sujeito e da realização vocacional (SPARTA, 2003 apud LASSANCE; LEVENFUS; SILVA, 2015).

Os autores destacam ainda que "A Teoria do Desenvolvimento Vocacional de Donald Super publicada no ano de 1953" permite entender o percurso que se estabeleceu em relação à orientação vocacional e gradativamente as teorias nessas áreas foram se organizando, e no Brasil foi realizado por Rodolfo Bohoslavsky em 1977. Mas para ele o processo se estenderia no decorrer de toda vida, embora o foco central ocorresse na adolescência.

A questão que se discute não é de analisar possíveis interpretações conclusivas ou generalizáveis para qualquer situação, mas sim apontar as múltiplas possibilidades envolvidas no contexto do qual o sujeito está inserido. A busca constante de novos casos e situações no cotidiano acadêmico apontam para uma estrutura comum da experiência de transição, considerando a transversalidade dos casos, tanto no contexto das escolas e consequentemente a universidade.

A participação da comunidade acadêmica (alunos e orientadores), somando-se a participação de diferentes profissionais, docentes da universidade atuantes no mercado de trabalho, literatura e material específico referente às carreiras, são fatores imprescindíveis na escolha da profissão em relação aos pretensos alunos. Nota-se que é importante preparar o aluno para a etapa do vestibular, despertando o seu espírito investigativo e, gradativamente com as transformações emocionais marcantes desta etapa 
de vida, a adolescência, fundamentando assim as escolhas futuras.

Em projetos de extensão o orientador que realiza intervenção utiliza de diversos recursos, objetivando facilitar a reflexão e a tomada de consciência por parte do orientando. Essa etapa pressupõe maior amadurecimento cognitivo e com capacidade de enfrentar novos desafios frente à decisão em relação à profissão, levando-o a perspectivas de identidade profissional e pessoal, vislumbrando a construção um projeto de vida.

Ademais o Projeto de Iniciação Científica de Extensão da UEMG parte desta ideia, tendo a finalidade de promover a integração com a UEMG - Universidade do Estado de Minas Gerais - MG” e prepará-los para os exames vestibulares, mas necessariamente possibilitar a escolha profissional em um cenário de constantes mudanças devido o surgimento de novas profissões. Neste artigo o objetivo central é descrever as ações de extensão para orientação vocacional de alunos que estão finalizando o Ensino Médio de Escolas Públicas na cidade de Frutal - MG.

\section{MATERIAL E MÉTODO}

Para a construção da proposta de extensão retratada no presente artigo, foi realizado um Encontro de Profissões em conjunto com todas as escolas públicas do município, abordando diferentes profissões, sendo proferidas palestras por profissionais e professores no período de dois dias consecutivos. $\mathrm{Na}$ oportunidade foi selecionado um representante de cada escola, que organizou o trabalho juntamente aos supervisores, diretores das respectivas escolas, definindo o planejamento das ações, com ênfase na aplicação do instrumento avaliativo, ou seja, teste específico de escolha vocacional.

Neste projeto extensionista foi atendido à população de alunos que estão concluindo o ensino médio nas Escolas Públicas de Frutal MG, cooperando assim para uma tomada de decisão mais consciente, enquanto os eles estão cursando o final do ensino médio. Vale ressaltar que em visita de alunos a universidade de outra cidade vizinha, manifestou-se o interesse de realizar in loco a aplicação do instrumento avaliativo vocacional, sendo assim foi deslocado dois participantes do projeto de extensão para atender a essa demanda.

O Projeto de Iniciação Científica de Extensão da UEMG, voltado para orientação vocacional, abrangeu desde docentes e discentes provenientes de cinco Cursos da universidade, Administração, Comunicação Social, Direito e Geografia, com a finalidade de aproximar os futuros alunos na Universidade, apresentando assim a possibilidade de participarem de um processo de escolha profissional no momento que estão finalizando o $2^{\circ}$ grau nas Escolas Públicas de Frutal-MG.

\section{RESULTADOS E DISCUSSÃO}

O projeto de orientação vocacional abarca uma série de ações que promovem a aproximação entre Universidade e Escolas. Das quais busca estabelecer três linhas de ações:

1. Apresentação de vídeos institucionais da Universidade e seus respectivos Cursos para 
os alunos de ensino médio a serem veiculados nas escolas de ensino médio. Com a temática: Venha conhecer a UEMG, do qual foi privilegiado o conteúdo estrutural da universidade. A Estrutura administrativa, Núcleos, Unidades, produções mais relevantes.

2. Visitas dos alunos das escolas públicas nas dependências da UEMG, promovendo a interação entre os alunos do ensino médio, os graduandos de todos os Cursos disponibilizados pela Universidade e os profissionais, dentre eles docentes e técnicos das diversas áreas de ensino da Universidade.

\section{Serviço de Orientação e Apoio}

Profissional, com o objetivo de proporcionar o maior número de informações aos futuros alunos, palestras explicativas e testes vocacionais que cooperem para uma escolha mais consciente das carreiras pretendidas pelos alunos.

Inicialmente, estabeleceu na primeira fase de investigações com temáticas voltadas para as áreas profissionais, para que um determinado público alvo escolhesse a profissão. Em uma segunda fase as palestras com profissionais das áreas de interesse e o contato entre alunos, professores e os próprios discentes da Universidade.

Já na terceira fase atividades diversas que pudessem proporcionar maior conhecimento de si e das profissões escolhidas, bem como dinâmicas de autoconhecimento, verificou-se as distintas carreiras, com informações especificas pensando no aspecto emocional que perpassa a escolha do sujeito.

Por último na quarta fase após o Trabalho de Orientação Vocacional/Profissional, propriamente dito, foi verificada, a assertividade das escolhas, conversando, entrevistando, os alunos, priorizando aqueles que continuavam com dúvidas em relação à certeza da escolha. A partir das análises verificaram-se os procedimentos adotados e metodologias, investigativa, que se pautava nas expectativas anteriores dos alunos. Ou mesmo se aconteceram dificuldades no decorrer do processo, como descrito:

Para muitos jovens a escolha da profissão no século XXI é uma dificuldade, mas ao mesmo tempo, uma necessidade. Numa época em que a tecnologia e a ciência caminham a passos largos, o jovem apresenta interesse em obter maiores informações sobre as novas opções de trabalho, mercado, cursos, faculdades etc. Além de se informar sobre as novas possibilidades de cursos, far-se-á necessário ao jovem conhecer-se, refletir sobre seus gostos, visão de mundo e sobre o que almeja para seu futuro, incluindo aí um projeto de vida pessoal que envolva o profissional (DÁTILO; LIMA, 2011).

De lá para cá foram inúmeras as mudanças, tanto que recentemente nesta proposta de extensão foi utilizado a tecnologia e a internet, realizando contatos com os professores, diretores das escolas, virtualmente, para otimizar o processo vocacional com os alunos.

\subsection{Ações realizadas e resultados esperados}

Os primeiros trabalhos de orientação na UEMG - Unidade Frutal, iniciaram-se por volta do ano de 2005, após um ano da abertura da mesma, que antes era uma Fundação, eram 
ministrados cursos de orientação vocacional em todas as escolas públicas e privadas de Frutal e algumas cidades circunvizinhas. Em 2007 a universidade foi estadualizada e continuaram os trabalhos de forma individual na própria instituição. Até que em junho de 2017, o trabalho passou a ser direcionado para as escolas públicas, tornou um projeto de extensão, sem bolsa, com a participação de 04 bolsistas de diferentes cursos, um projeto interdisciplinar. Várias ações incidiram e a pretensão é dar continuidade ao mesmo, já que existe uma demanda por parte das escolas e alunos para a escolha de profissões. Por sua vez a universidade valoriza o interesse da comunidade educacional, contribuindo para a execução da referida proposta.

A duração do trabalho de extensão se estenderá por, no máximo, 08 meses, de 01/06/2017 a 30/03/2018, tempo necessário para atingir os objetivos predeterminados, realizar o trabalho necessário com os alunos e sanar as dificuldades iniciais para implantação do projeto.

E atender concomitantemente as devidas adaptações relacionadas à demanda dos alunos, seja elas de interesse e escolhas profissionais, intelectuais. Ou até mesmo possíveis dificuldades durante o percurso, as tomadas de decisões, mas principalmente estabelecer discussões acerca da referida proposta de extensão, organizar a equipe e caso necessário acrescentar novos profissionais ou alunos internos ou externos, elaborar os relatórios e artigo referente ao assunto em pauta.

A UEMG Unidade de Frutal, em contrapartida, fornecerá o ambiente físico para encontros com a orientadora, salas de atendimento, computadores, biblioteca para leitura e pesquisa e consulta do acervo disponível. O orientador financiará a extensão através de recursos próprios e terá a participação de alunos e outros voluntários da comunidade e clubes de serviços.

De maneira geral, o projeto em pauta é expandido para a cidade de Frutal/MG, e posteriormente poderá ser executado na integra ou parcialmente nas Unidades da UEMG, do Estado de Minas Gerais, utilizando-se da metodologia e/ou formas de financiamento, parcerias locais, entre outras modalidades que possam somar e enriquecer a proposta inicial. É imprescindível a necessidade de se realizar projetos de orientação vocacional/profissional com os jovens que pretendem ingressar na Universidade.

Adentrar este terreno de muitas possibilidades é por si só, bastante fascinante. Mas, é também assumir os riscos de um caminho pouco explorado. Espera se que com ideias, novas propostas no futuro sirvam de parâmetro para a realização de novos trabalhos que possam compreender melhor a escolha de um determinado curso e a construção de projetos profissionais para os estudantes da UEMG, como para alunos externos.

Esta ação de extensão realizada na cidade de Frutal/MG possibilita ampliar a produção de conhecimentos referentes a essa área de atuação e desenvolver estratégias de intervenção que possam atender mais eficazmente os alunos. Entretanto, no que tange aos orientadores em relação à continuidade do projeto de extensão, cabe fazer as devidas adaptações na apresentação 
das atividades, de acordo com o perfil e necessidades do grupo de participantes, mas essencialmente pautando o trabalho em referenciais teóricos e técnicos que venham favorecer uma adequada formação da turma e leitura.

E preponderantemente formar vínculos positivos com os orientandos, para que se possa criar um verdadeiro canal de comunicação entre todos os envolvidos na proposta, estruturando os encontros, de forma a minimizar um possível índice de faltas e desistências por parte dos alunos/participantes. As práticas de orientação profissional podem proporcionar por parte dos orientandos, mais interesse e motivação aos extensionistas expandindo sua visão de mundo e de trabalho.

O aporte de projetos de extensão pode conduzir encontros de importância substancial para o enriquecimento técnico de sua formação acadêmica, na medida em que puderam articular ensino, pesquisa e extensão. Mobilizando o constante desenvolvimento de comunidades e sem dúvida na ampliação de redes de apoio.

A construção do conhecimento, bem como aprender novas maneiras de se trabalhar em projetos extensionista e somando ao trabalho com professores, são formas em adquirir experiência profissional e interpessoal, a qual é requerida pelo mercado de trabalho.

\section{CONSIDERAÇÕES FINAIS}

Percebe-se que muitos fatores podem comprometer o rendimento nos estudos dos alunos à medida que aceitam a dupla tarefa de trabalhar e estudar, por vezes a eles imposta, ou deixado como tarefa secundária. Equilibrar, lazer, convivência social, escola, estudos para a formação profissional e trabalho não costuma ser tarefa simples.

Por outro lado, cabe apontar que muitos dos jovens provenientes de famílias das camadas populares veem no estudo a possibilidade de ascensão econômico-social, pois entendem que poderão obter melhores empregos e salários. Em geral as alternativas disponíveis e que proporcionem às pessoas em situação socioeconômica e materiais insatisfatórios e o desenvolvimento de habilidades, competências que revertam sua condição e lhes coloquem em situação de equidade diante de estudantes e profissionais advindos de famílias com maior renda e nível de escolaridade avançado.

Diferentemente daqueles alunos que são provenientes de classe média, que se preparam para um curso superior e para a construção de uma carreira, veem-se inseridos ou em preparação para entrarem no mercado de trabalho logo após a conclusão do ensino médio ou mesmo sem a educação básica concluída.

De toda forma, seja qual for a classe que o indivíduo pertença, o aspecto mais relevante é não impor ou interferir na escolha, pois cabe a ele administrar a vida profissional, como um passo a ser dado para a sua carreira futura, por sua vez, são fatores determinantes no que tenciona concomitantemente um verdadeiro projeto de vida.

Portanto, o ingresso no ensino superior é uma transição que traz um leque de 
potencialidades e acentuadas repercussões para o desenvolvimento psicológico dos jovens estudantes. Despertando um senso de identidade autônomo e a tentativa esta traduzida por meio da escolha, ademais nem sempre a profissão escolhida pelos jovens possui um caráter central na constituição da identidade em si.

Para alguns, o simples fato de ingressar no ensino superior e identificar-se como estudante universitário parece ser um aspecto mais saliente do que a própria profissão, neste aspecto a escolha pode não se apresentar como o mais relevante para o sujeito. Percebe-se que a experiência universitária não se resume exclusivamente à formação profissional, pois a entrada na universidade implica em uma série de transformações nas redes de amizade e também de apoio social com os demais estudantes.

Nos dias de hoje, o mundo globalizado e fundamentalmente tecnológico passa por mudanças acentuadas impactando significativamente o universo do mercado de trabalho. Portanto este cenário caminha para alavancar profissões mais afinadas com a vida do indivíduo e este necessariamente precisa se adaptar às mudanças sociais. Portanto alguns aspectos devem ser considerados e analisados com a finalidade de se alcançar a eficácia na orientação vocacional, entre eles: o papel do profissional, que não deve apenas informar sobre as profissões, e sim, empenhar na questão de obter o autoconhecimento e essencialmente a escolha em si. Escolhas estas que podem perdurar ou mesmo sofrer transformações durante toda uma vida.
A orientação profissional se caracteriza por fatores de desenvolvimento pleno que perpassam os períodos da infância, adolescência e vida adulta, chegando à velhice. Nesse sentido quanto mais estiverem conscientes, decididos por uma determinada escolha, poderão ser capazes de enfrentar as adversidades aprendendo a conhecerse cada dia mais.

\section{REFERÊNCIAS}

ALMEIDA, Rosemarie Elisabeth Schimitid. Relato de experiência: projeto de extensão: orientação vocacional e profissional de adolescentes das escolas estaduais da cidade de londrina e região. UEL. Universidade Estadual de Londrina - PR. Revista Espaço Para Saúde. Londrina. v15. Suplemento N.1.p. 418-424. JUN. $2014 . \quad$ Disponível em: file:///C:/Users/User/Downloads/19623-82852-1PB\%20(1).pdf. Acesso 07 de Dez. de 2017.

DÁTILO, Gilsenir Maria Prevelato de Almeida. LIMA, Vanilda Gonçalves de. Orientação profissional - universidade ajuda os jovens a encontrar caminhos profissionais: relato de intervenção. 2011. Revista do Laboratório de Estudos da Violência da UNESP/Marília. Disponível em: http://www.levs.marilia. unesp.br/revistalevs/edição7/autores/RelatoPesqui sa1-OrientacaoProfissional.pdf/ Acesso em 21 Mai. de 2017.

MELO-SILVA, Lucy Leal. NOCE, Mariana Araujo. ANDRADE, Patrícia Pasqua. Interesses em adolescentes que procuram orientação profissional. Psic [online]. 2003, vol.4, n.2, pp. 06-17. ISSN 1676-7314.

OLIVEIRA, Natália de Quadros. PESSOA, Roberto Calmon. A importância da orientação profissional para o direcionamento de carreira na adolescência. www.psicologia.pt. ISNN 1646$6977 . \quad$ Disponível em: http://www.psicologia.pt/artigos/ textos/TL0343.pdf. Acesso 08 de Dez. de 2017.

LASSANCE, Maria Célia Pacheco. LEVENFUS, Rosane Schotgues. SILVA, Lucy Leal Melo (org.) 
Orientação de carreira: investigação e práticas

- Porto Alegre: Associação Brasileira de Orientação Profissional, 2015362 p.: il. Livro Eletrônico ISBN 978-85-69762-02-7. Disponível em: https://drive.google.com/file/d/0BzcegOM3ihMRVVTa0pIYkk5YVB3Z1 VmblYyd U05SlhaS2dN/view. Acesso 08 de Dez. de 2017.

TEIXEIRA, Marco Antônio Pereira. DIAS, Ana Cristina Garcia. WOTTRICH, Shana Hastenpflug. OLIVEIRA, Adriano Machado. Adaptação à universidade em jovens calouros. Psicol. esc. educ. [online]. 2008, vol.12, n.1, pp. 185-202. ISSN 1413-8557.

\section{Como citar este artigo (Formato ABNT):}

TACELI, Izabel Cristina; SANTOS, Geisiane Rodrigues dos. Orientação vocacional em uma universidade pública do Estado de Minas Gerais: um olhar para o futuro. Educação, Psicologia e Interfaces, vol.1, n.2, p. 68-77, 2017. DOI: https://doi.org/10.37444/issn-2594$\underline{5343 . v 1 i 2.41}$

Recebido: 02/11/2017.

Aceito: 23/12/2017. 